BMJ Open

Sport \&

Exercise

Medicine

\title{
Novel coaching cricket bat: can it be used to enhance the backlift and performance of junior cricket batsmen?
}

\author{
M Habib Noorbhai, ${ }^{1,2}$ Russell C Woolmer, ${ }^{2}$ Timothy D Noakes ${ }^{2,3}$
}

To cite: Noorbhai MH, Woolmer RC, Noakes TD. Novel coaching cricket bat: can it be used to enhance the backlift and performance of junior cricket batsmen?. BMJ Open Sport Exerc Med 2016;2:e000141. doi:10.1136/bmjsem-2016000141

- Prepublication history for this paper is available online. To view these files please visit the journal online (http://dx.doi.org/10.1136/ bmjsem-2016-000141).

Accepted 13 August 2016

CrossMark

\footnotetext{
${ }^{1}$ Department of Sport Management, Faculty of Business, Cape Peninsula University of Technology, Cape Town, South Africa ${ }^{2}$ Cricket Science (Pty) Ltd and 149, South Africa

${ }^{3}$ Division of Exercise Science and Sports Medicine, Department of Human Biology, Faculty of Health Sciences, Sports Science Institute of South Africa, University of Cape Town, Cape Town, South Africa
}

Correspondence to Habib Noorbhai; NoorbhaiM@cput.ac.za

\section{ABSTRACT}

Background: In the current literature, it is questionable whether cricket bats in their current form and dimensions allow a young cricketer to hit the ball effectively. The aim of this study was to test the effectiveness of a novel coaching cricket bat among junior cricket batsmen with regard to enhancing performance and the direction of the backlift.

Methods: A cross-sectional research study with analytical research methods was employed, in which 2 groups (coached: $n=12$ and uncoached: $n=35$ ) of participants (ages 9-13) took part in a pilot and intervention study. Participants were required to use a novel coaching cricket bat in a coaching game format. Biomechanical and video analysis was conducted in the frontal and lateral planes. Effect sizes (ES) were calculated to determine the effectiveness and the level of significance was set at $p<0.05$.

Results: Pilot study results demonstrated that participants scored an additional 100 runs when using the coaching cricket bat compared with a conventional cricket bat $(p=0.003) .6$ weeks postintervention (training with the coaching cricket bat), the experimental group displayed improved performance $(E S=5.41)$. Players' backlifts had subsequently become more lateral, which may have promoted more effective ball striking as a result of this training effect.

Conclusions: The recommendation from this study is that coaches should encourage young cricketers to use the coaching cricket bat as it is perceived to be a potentially significant training aid for enhancing their performance and the direction of their backlift when they use conventional cricket bats in match play.

\section{INTRODUCTION}

A batting technique consists of many elements such as the stance, grip of the bat, backlift, initiation, downswing and followthrough. ${ }^{1}$ One of the key components of the overall batting technique is the backlift, which is the movement of the bat just before the batsman initiates the batting downswing prior to making impact with the ball. ${ }^{2}$ It can be described as a technical component of batting in which its traditional movement is limited to a linear plane. ${ }^{3}$

\section{What are the new findings?}

- The coaching cricket bat might be a promising training aid to train young cricket batsmen (ages $5-11$ ) for striking the ball with power and timing.

- The coaching cricket bat, together with the training drill of hitting the ball against the wall may have a positive effect on the direction of the backlift of young cricketers and may also serve as a promising training tool if used for a minimum of 4 weeks.

- Owing to its weight component and dimensions, the coaching cricket bat may assist the young cricketer in formulating a lateral backlift, which can potentially enhance batting performance in the long term.

How might it impact on coaching practice in the near future?

- Batting training against a wall might assist young cricketers to adopt a more looped batting technique, whereas the coaching cricket bat may produce potential improvement of batting performance over a longer period.

- Coaches might encourage young cricketers to use the coaching cricket bat as it is perceived to be a potentially significant training aid for enhancing their batting performance and backlift when they use conventional cricket bats in matches.

- Since a training effect can only be produced among players over a longer period and, also bearing in mind that variances of learning abilities exist between individuals, the coaching cricket bat might have positive effects among young cricket players in terms of adapting their performance and change in batting technique.

The mechanics of the backlift are poorly understood; ${ }^{45}$ however, qualitative biomechanical analyses of movement in sports are key to understanding performance. ${ }^{6}$ Biomechanical analyses can provide important insights into the biomechanics of technique in sports, especially in those skills that have to satisfy parallel performance outcomes by choosing from a set 
of joint angles in the frontal or lateral planes. ${ }^{7-9}$ Cricket coaches have been teaching batting techniques to cricketers at various levels since the inception of the game. One such technique that is advocated is the straight batting backlift technique (SBBT). ${ }^{10}$ The technique emphasised taking the bat directly over the middle stump.

However, there is no recommendation about the direction in which the bat face should be pointing. The assumption may have been that the bat face must also point directly backwards. ${ }^{11}$

Most coaching literature continues to advocate this traditional norm in which the backlift of the bat is in the direction of the wicket-keeper, towards the stumps or towards the slips. ${ }^{11}{ }^{13-17}$ However, this method is not the one adopted by some of the world's most successful batsmen. $^{18}$

Path tracings of Australian international batsmen $(n=9)$ showed that their bats follow a distinctive loop in which the path of the bat deviated well outside the mean alignment of the shoulders to reach an average maximum angle in the transverse plane of $47 .{ }^{19}$ It is unclear why this occurred, other than the possibility that increasing the range of different strokes of which the batsmen would be able to execute a more looped backlift.

The lateral batting backlift technique (LBBT) is one in which the bat is lifted laterally in the direction of second slip. ${ }^{18}$ Using this technique, both the toe of the bat and face of the bat point directly towards the off-side (usually between slips and point). With the SBBT, the toe of the bat is directed towards the stumps and/or the face of the bat points towards the ground or the wicket-keeper. ${ }^{18}$

Most successful international batsmen and uncoached cricketers $(77 \%)$ used an LBBT, whereas coached cricketers used an SBBT (23\%). Batsmen who used an LBBT also had an open face of the bat (the bat face in the direction of point or towards the off-side). This finding is the opposite of what coaching manuals advocate. ${ }^{18}$

We thereafter sought to investigate the backlift further in a follow-up research study among coached and uncoached cricket players. If players are not coached, they tend to strike the ball using an LBBT. $^{20}$ This finding may suggest that early coaching emphasising the traditional SBBT could be disadvantageous to the young cricketer, whereas perhaps the LBBT could produce superior long-term outcomes. ${ }^{20}$

As such, technique forms a key component in cricket and enhancing the understanding of cricket batting biomechanics, skill acquisition and assisting cricket coaches to develop efficient batting skill development programmes is imperative. ${ }^{21}$ However, coaches often find it difficult to design the most effective batting skill practice structures or programmes. ${ }^{21}$ In addition, there is limited empirical evidence to assist coaches to develop an evidence-based approach.

In the light of these issues, it is particularly challenging for most coaches to coach a backlift in the lateral direction or as a looped technique. Furthermore, though the backlift has been shown to be a contributing factor to successful batsmanship, there is currently no evidence showing which backlift technique type promotes better run scoring and performance.

Therefore, a novel coaching cricket bat was conceptualised that has weight on either sides towards the distal end of the bat, but which also weighs significantly less than a conventional cricket bat used by junior cricketers. The conceptualisation of the dimensions of the bat originated from combining a cricket bat and tennis racquet into one model (figure 1). The coaching cricket bat has been conceptualised, designed, manufactured and patented in South Africa (Design Registration number: F2013/01526, updated cricket bat, class 21, part F).

\section{Research aims}

There is presently no evidence that a cricket bat in its current form and dimensions allows a young cricketer to train effectively so that he or she can hit the ball with more power and efficient timing in a match situation. There has been limited investigation into improving the performance of batting among junior cricketers in the form of a revised or newly conceptualised coaching cricket bat. Therefore, the purpose of this study was to test the effectiveness of the novel coaching cricket bat among junior cricket batsmen. We wished to test the hypothesis that this novel coaching cricket bat would enhance their performance and influence the direction of the batting backlift technique.

\section{Hypothesis}

We hypothesised that there would be alterations in the backlift technique of cricketers who use the novel coaching cricket bat for more than 4 weeks.

\section{METHODOLOGY}

\section{Research design}

A cross-sectional research study was employed in which observational and analytical research methods were used. This study contained two components, a pilot study and an intervention study.

\section{Participants}

The coaching cricket bat was tested among male and female uncoached participants $(n=35)$ aged $10-13$ years, prior to the intervention in the Western Cape, South Africa. Players who participated in the intervention study were male junior cricketers $(n=12)$ aged 9-10 years, also from the same study setting.

\section{Ethical considerations}

Information leaflets were distributed to participants, and informed consent forms as well as child assent forms were obtained from all participants and their parents prior to their participation in the study. Ethical approval for the study was granted by the Human Research Ethics Committee of the University of Cape Town (HREC: 
Figure 1 The coaching cricket bat in the frontal, rear, side-on and aerial views.

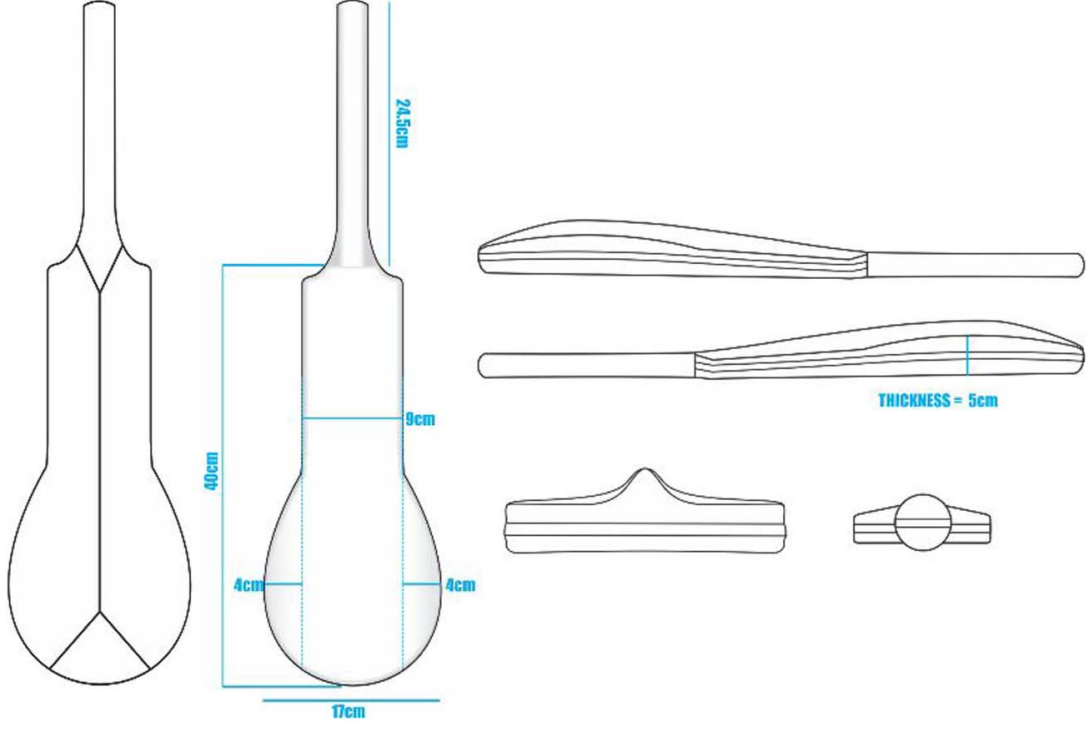

586/2014 and HREC: 327/2015). This research study conforms to the World Medical Association Declaration of Helsinki on Ethical Principles for Research Involving Human Subjects.

\section{Study procedure}

The pilot study

The purpose of the pilot study was to test the use of the coaching cricket bat and to study how players responded while playing with the bat. This was done by comparing it to a conventional (normal) bat as well as to document how players responded to the coaching cricket bat in a match situation. A conventional cricket bat was used first before the novel coaching cricket bat was introduced. Three balls per bat were bowled in order to match the three varied lengths in cricket (short, back of a length and full). As such, six balls were thrown to each player (3 balls facing a normal cricket bat and 3 balls facing the coaching cricket bat with varied lengths of deliveries) facing the same bowler (figure 2). The researchers had considered the use of the bowling machine to ensure standardisation of ball deliveries during the study. However, the objective of the study was to mimic a match situation and environment in which the same player bowled to the same batsman. In the event that the ball was not delivered of the desired length or line, the bowler was asked to rebowl the ball.

The normal bat used in the pilot study weighed $900 \mathrm{~g}$ and the coaching cricket bat weighed $575 \mathrm{~g}$. In the intervention group, the coaching cricket bat also weighed $575 \mathrm{~g}$; and the weight range of the conventional bats used by each player was from 850 to $950 \mathrm{~g}$.

In addition, one ball per length was used in order to measure the instinctive response from the player. Facing a second or third ball of the same length delivery might have allowed the player to get used to the ball thrown; hence, six deliveries was deemed to be effective for the pilot study. When participants batted with either the coaching or conventional cricket bats, the deliveries were not changed, allowing for the measures and responses from participants to be consistent. The pilot study was performed in a day, which took $\sim 3$ hours on
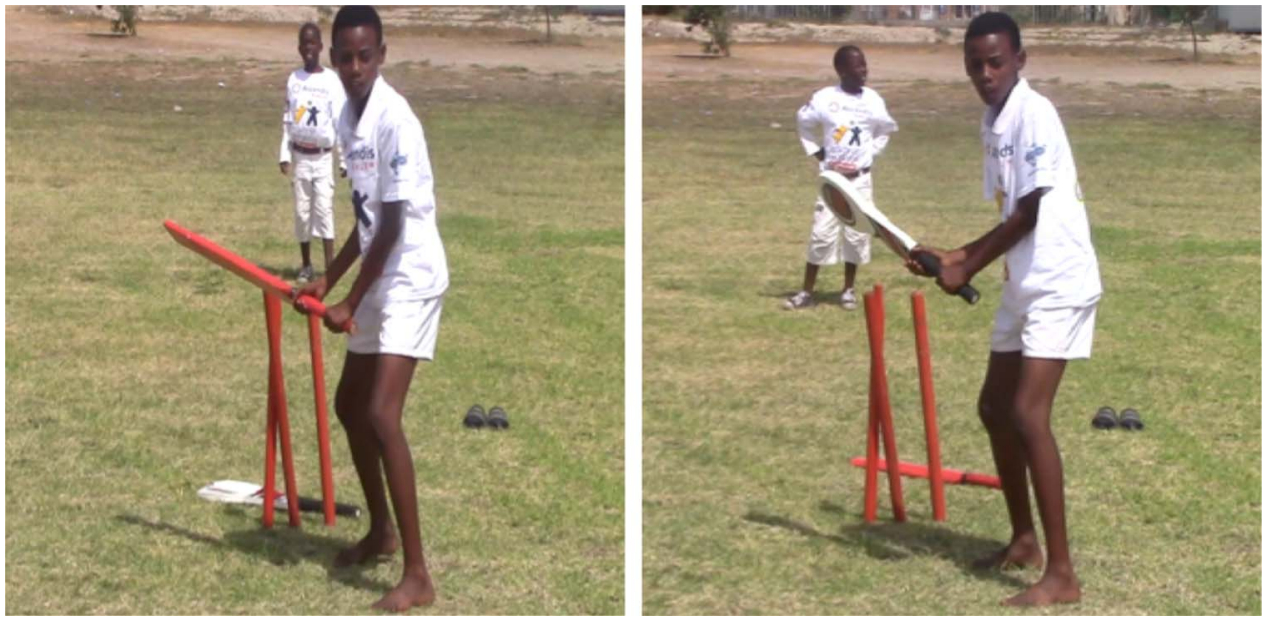

Figure 2 Uncoached player using both the normal bat (right) or coaching cricket bat (left) 
Figure 3 Players hitting the ball against the wall continuously with a 'looped' technique.
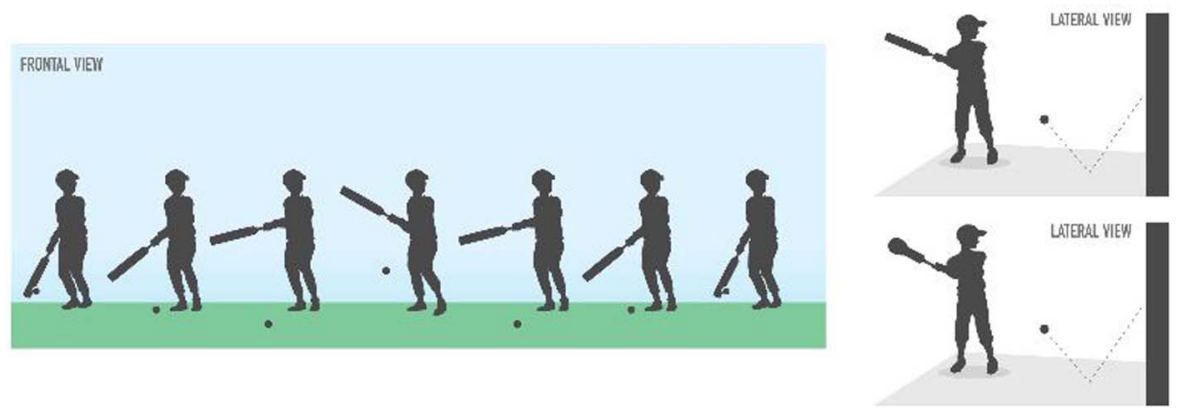

the field including a warm-up for all of the 35 participants.

Since the pilot study had shown that the coaching cricket bat was more suited to junior players aged 9-11 years, we included players within this age range for the intervention study. There was no randomisation in the pilot study and the players from this group belonged to the same cricket club. Seeing that the pilot study was only done on one match, the comparison of runs scored between the two bats used by each player is just an indication of how the bat could possibly work in an intervention trial over a longer time period (ie, 6 weeks).

\section{The intervention study}

Seven months after the pilot study, further research was conducted using an intervention of 6 weeks among young players coached the traditional way in which they had been taught to lift their bats in the direction of the wicket-keeper or first slip.

Coached junior cricket players $(n=12$; aged $9-10$ years) were recruited. A randomised controlled study design was administered in which the cricket players randomly obtained a number from a hat and were subsequently required to train and play within that group (either control or experimental). Randomisation had taken place in the intervention group in which the players had played for the same school but for different teams with similar age groups.

The experimental group was required to train daily using the coaching cricket bats, whereas the control group was required to train daily with their normal bats. Players from both groups were asked to hold their respective bat with both hands and hit a tennis ball against the wall continuously with a 'looped' technique (figure 3).

Parents and coaches were asked to assist in reminding the participants to practise with their required bat for the 6-week period, whether it was at home or in formal practice structures such as at the nets or on the cricket field. In addition, cricket coaches were assigned 3 days a week to ensure that the training was conducted with the players' required bat during formal practice sessions. During feedback sessions, parents and coaches confirmed that the participants had trained with their required bats on a daily basis.

During the prematch (week 1) and postmatch (week 6) weeks, the two groups of six players each played a mini-

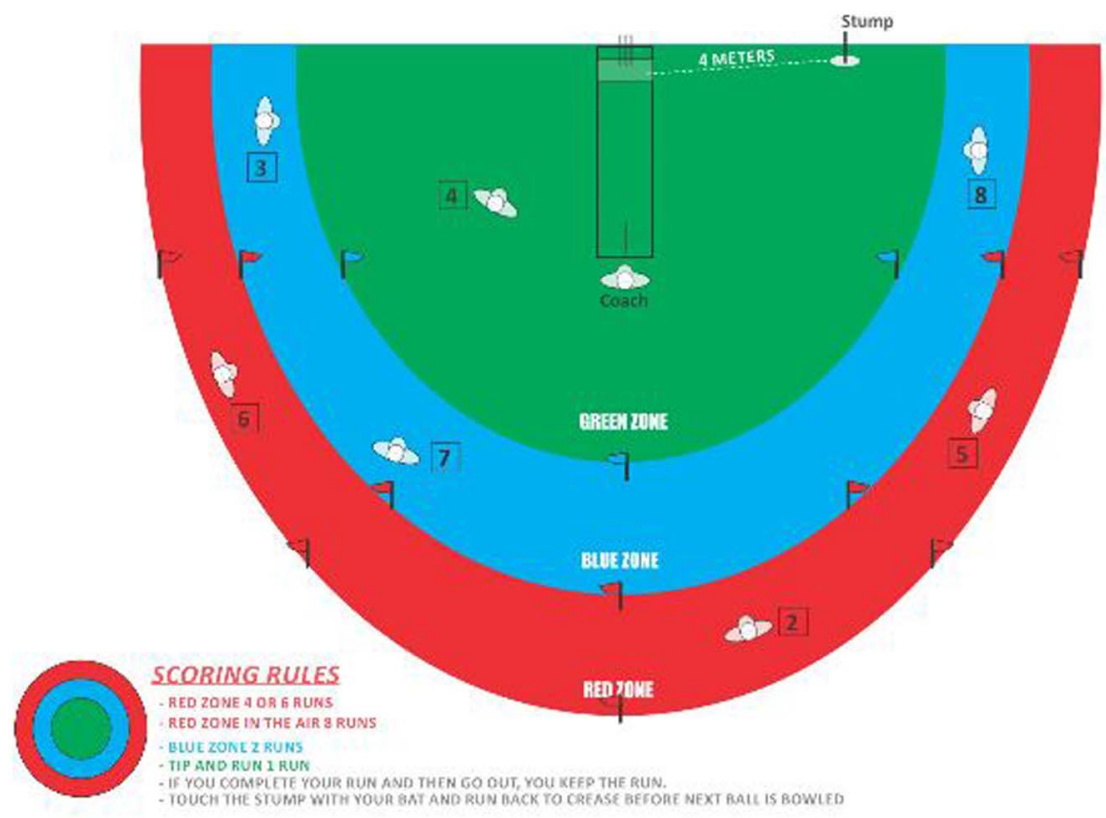

-8 players per side

-1 batsmen in at a time

Test match style play 2 innings per team

- One hand one bounce

- Game designed to be quick and continuos

Fielding team

-3 red zone fielders

3 blue zone fielders

- 2 green zone fielders, incl. keeper

- Coach is always part of fielding team

\section{Ways to go out}

- Caught (one hand one bounce)

- Bowled

Run out keepers or bowlers end

- Hit wicket

Figure 4 A visual description of the cricket coaching game. 


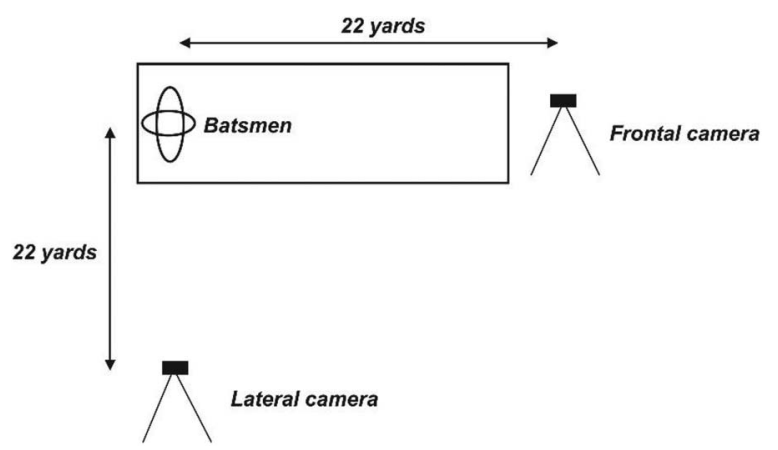

Figure 5 Camera setup for the intervention study in the frontal and lateral views.

cricket game against each other on the cricket grounds in the form of a cricket coaching game (figure 4) at a suitable time for both parents of the participants and the researcher. Each batsman faced six balls delivered by the same bowler in prematch and postmatch games. Warm-up sessions were provided in the prematch and postmatch sessions. Players were encouraged to score as many runs as possible from the six deliveries. Team scores were then calculated and compared with each other.

We considered blinding players to the bats that they were going to use. However, this was not possible as the players using the coaching bat would see and feel the difference from the standard cricket bat. It could be argued that players in the pilot study group may have had an increase in confidence that resulted in better performance. However, in the intervention study, players in the experimental group had used the coaching bat daily for 6 weeks, which implies that it was not necessarily just an increase in their confidence.

\section{Description of the cricket coaching game}

The cricket coaching game was designed to improve the batting performance of young cricketers. Instead of the usual circular boundary in cricket, the game consisted of a semicircle in which players could only score runs in front of the wicket/square. This was to motivate players to hit the ball in front of square (figure 4).

\section{Biomechanical and video analysis}

Biomechanical and video analyses were performed with both groups. This analysis included the measurement of a photo sequence with drawing tools and a static angle calculation of the batsman's technique using the Kinovea (V.0.8.15) software package.

Canon LEGRIA HF R506 High Definition Camcorder video cameras were used to capture video footage of the players, and were attached to a laptop computer. An external hard drive from the video camera was inserted into the laptop for further usage of the software. Cones were placed (at each of the 3 legs of the tripod stand) to control for accurate camera distances between the camera and participants as well as the angles for video recording. The frontal camera was situated 22 yards in front of the participant (due to pitch length at junior cricket level being roughly 22 yards) and the lateral camera was also situated 22 yards perpendicular to the batsman at a $90^{\circ}$ angle to the frontal camera (at point region) (figure 5).

The analysis was performed similarly to other studies ${ }^{1819}$ in which the initial movement of the batsman was determined from the first frame before the initiation of the backlift while initial movement patterns of the bat were assessed qualitatively by viewing the footage. In the frontal plane (frontal view), the backlift represented the period from the initiation of the backlift to the maximum vertical displacement of the toe of the bat. The still photo from the video footage was selected immediately before the bowler released the ball. These picture frames were then used to determine the type of batting backlift technique for each type of delivery bowled. Variables of interest included the direction of the backlift and where the face of the bat was directed during the backlift. In the transverse plane (lateral view), variables of interest included whether the face of the bat was open or closed. All these analyses were performed on both study groups.

\section{Classifiers}

Classifiers were used to identify the type of batting backlift technique employed by all batsmen. These classifiers were coded as 1 (bat face facing straight back and towards the wicket-keeper or the ground), 2 (bat face facing first or second slip) and 3 (bat face towards gully or point). If the bat was directed straight back or towards the slips/gully regions but has an open face of the bat, it was still classified as classifier 3. Angle ranges were conceptualised to determine these classifiers (1: between $0^{\circ}$ and $25^{\circ}$ ), (2: between $25^{\circ}$ and $45^{\circ}$ ), (3: between $45^{\circ}$ and $80^{\circ}$ ).

For the purpose of this study, the toe of the bat was defined as the vector orthogonal to the toe being the pointer. ${ }^{22}$ This strengthens the validity and reliability of the analysis as the backlift can be readily detected and analysed at different positions and time points in the lift. ${ }^{23}$ Drawing a vector is a common approach to defining the toe of the bat and how it will point in a particular direction. ${ }^{6}$ Lines and vectors were drawn (1) vertically, from the head to the hands (green line), (2) horizontally, to show where the hands rested (blue line) and (3) obliquely, to show the direction of the bat during the backlift (red line) (figure 6). The still photo (captured from the video footage) was analysed immediately after the bowler had released the ball. These lines created an angle to show how far away the bat was from the body in the frontal plane and how much bat rotation occurred before the bat made contact with the ball.

We accounted for perspective error by limiting the type of videos observed as well as including horizontal lines in the background.

\section{Quantitative data analysis}

STATISTICA 11 analysis software was used for all statistical analyses. Descriptive statistics were calculated and 
Figure 6 Lines and vectors drawn to depict the angle of the backlift.

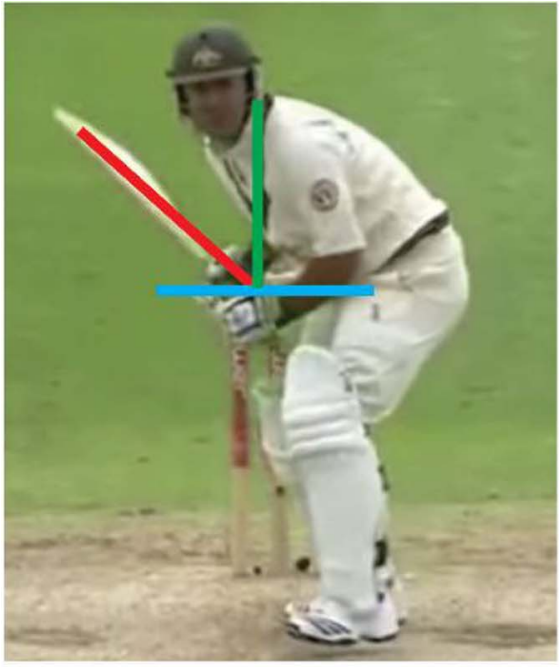

Right-Handed Batsmen

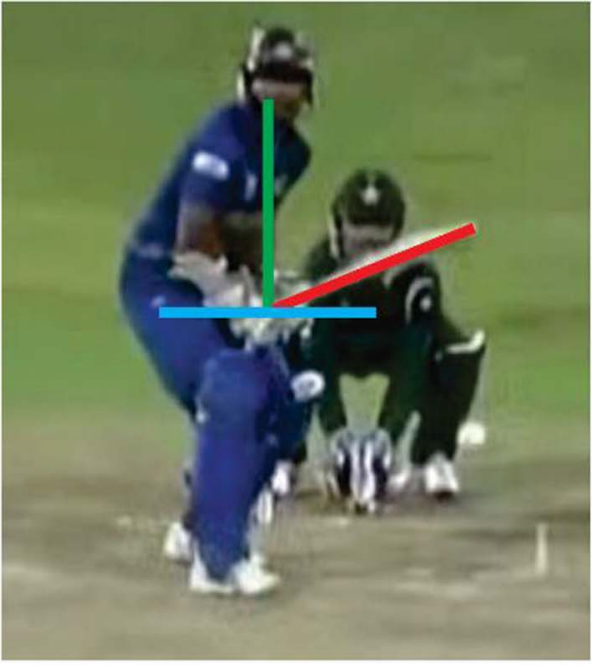

Left-Handed Batsmen results were represented as means and SDs for continuous variables. The level of significance was set at $\mathrm{p}<0.05$ for measuring the difference in runs scored between the normal bat and coaching cricket bat in the pilot study. Cohen's d effect sizes (ES) were also calculated to determine the effectiveness of both groups between the prematch and postmatch in the intervention group. According to Sullivan and Feinn, ${ }^{24}$ medium and large ES are more than 0.5 and 0.8 , respectively. As such, the level of significance for medium and large ES for this study was set at ES $>0.5$ and $>0.8$, respectively.

\section{RESULTS}

\section{Batting performance}

In the pilot study, participants $(\mathrm{n}=35)$ scored 100 runs more with the coaching cricket bat than with the normal bat $(p=0.003)$ (table 1$)$. A total of 224 runs from 105 balls $(35 \times 3$ balls; $213.3 \%$ strike rate $)$ were scored with the normal bat, whereas 324 runs from 105 balls (308.5\% strike rate) were scored with the coaching cricket bat. In cricket, a strike rate is defined for a batsman as the average number of runs scored per 100 balls faced. Consistent with a previous study, ${ }^{20}$ a vast majority of the uncoached cricketers $(80 \% ; n=28)$ in the pilot study were also shown to have an LBBT.

In the intervention study, the experimental group scored an additional 16 runs (double the amount from the prematch) in the postmatch $(\mathrm{ES}=5.41)$ (table 2).

\section{Direction of the backlift}

In the intervention study, the participants' backlift in the control group remained straight back when comparing prematch versus postmatch measures (tables 4 and 5). In the transverse plane (table 6), most of the participants' $(n=5)$ bat faces were closed or in the direction of the wicket-keeper and/or the stumps. In the experimental group, the participants' backlift was more lateral when comparing the prematch to the postmatch (tables 3 and
4). In the transverse plane, most of the participants' $(n=5)$ face of the bat was open facing towards the off-side (table 7).

\section{DISCUSSION}

The main findings of this study showed that the novel coaching cricket bat might be a promising training aid that can be used to train young cricket batsmen (ages 5-11) in order to develop the potential for striking the ball with power and timing. Another finding of this study has also shown that the coaching cricket bat together with the training drill of hitting the ball against the wall may have a positive effect on the backlift used by young cricketers.

Since the weight and angular momentum of the bat on pick up allows a player to lift the bat in a lateral direction, it also assists a young cricketer to lift their bat wider than second slip with an open face of the bat before making impact with the ball. In addition to the physical characteristics of the bat, the grip of the bat also has a wider circumference than normal cricket bats that makes it easier for players to place their hands comfortably on the bat and grip the bat. A fundamental question is: what impact would coaching have had during the intervention on batting performance in the experimental group, specifically on the hand position? This would entirely depend on whether the coach emphasised other elements of the batting technique aside from what the participants were required to execute as described in the methodology.

There is currently no recommendation on how to technically coach a backlift. Therefore, coaching during the intervention might have hindered the batting performance in the experimental group. It is advised that young players use the coaching cricket bat in training and to specifically hit the ball against a wall to acquaint themselves with the bat. 
Table 1 Total runs scored among uncoached cricket players during the pilot study $(n=35)$

\begin{tabular}{|c|c|c|c|c|c|c|c|c|c|}
\hline \multirow[b]{2}{*}{ Age group (gender) } & \multirow[b]{2}{*}{$\mathbf{N}$} & \multicolumn{4}{|c|}{ Normal bat (A) } & \multicolumn{4}{|c|}{ Coaching bat (B) } \\
\hline & & Ball 1 & Ball 2 & Ball 3 & Total A & Ball 1 & Ball 2 & Ball 3 & Total B \\
\hline & 1 & 0 & 0 & 2 & 2 & 4 & 0 & 2 & 6 \\
\hline & 2 & 6 & 6 & 4 & 16 & 6 & 6 & 6 & 18 \\
\hline & 3 & 0 & 2 & 2 & 4 & 4 & 0 & 6 & 10 \\
\hline & 4 & 0 & 0 & 2 & 2 & 0 & 2 & 2 & 4 \\
\hline & 5 & 2 & 0 & 4 & 6 & 4 & 4 & 4 & 12 \\
\hline \multirow[t]{6}{*}{ U11 (boys) } & 6 & 2 & 0 & 0 & 2 & 2 & 0 & 2 & 4 \\
\hline & 7 & 0 & 6 & 6 & 12 & 2 & 0 & 2 & 4 \\
\hline & 8 & 0 & 0 & 2 & 2 & 2 & 4 & 2 & 8 \\
\hline & 9 & 4 & 4 & 0 & 8 & 2 & 2 & 6 & 10 \\
\hline & 10 & 0 & 4 & 4 & 8 & 6 & 6 & 2 & 14 \\
\hline & 11 & 4 & 2 & 0 & 6 & 4 & 0 & 6 & 10 \\
\hline \multirow[t]{7}{*}{ Total } & & 18 & 24 & 26 & 68 & 36 & 24 & 40 & 100 \\
\hline & 1 & 0 & 0 & 2 & 2 & 0 & 2 & 0 & 2 \\
\hline & 2 & 6 & 4 & 0 & 10 & 2 & 2 & 4 & 8 \\
\hline & 3 & 0 & 2 & 0 & 2 & 6 & 6 & 4 & 16 \\
\hline & 4 & 2 & 6 & 6 & 14 & 0 & 6 & 6 & 12 \\
\hline & 5 & 2 & 2 & 0 & 4 & 2 & 6 & 2 & 10 \\
\hline & 6 & 2 & 2 & 2 & 6 & 2 & 2 & 6 & 10 \\
\hline \multirow[t]{6}{*}{ U12 (boys) } & 7 & 4 & 6 & 4 & 14 & 2 & 6 & 2 & 10 \\
\hline & 8 & 2 & 2 & 0 & 4 & 0 & 6 & 6 & 12 \\
\hline & 9 & 0 & 4 & 0 & 4 & 2 & 2 & 2 & 6 \\
\hline & 10 & 0 & 2 & 2 & 4 & 6 & 0 & 6 & 12 \\
\hline & 11 & 0 & 0 & 4 & 4 & 0 & 4 & 6 & 10 \\
\hline & 12 & 0 & 6 & 6 & 12 & 0 & 2 & 2 & 4 \\
\hline \multirow[t]{7}{*}{ Total } & & 18 & 36 & 26 & 80 & 22 & 44 & 46 & 112 \\
\hline & 1 & 0 & 0 & 0 & 0 & 0 & 4 & 2 & 6 \\
\hline & 2 & 4 & 6 & 2 & 12 & 0 & 4 & 4 & 8 \\
\hline & 3 & 0 & 0 & 2 & 2 & 6 & 6 & 6 & 18 \\
\hline & 4 & 2 & 2 & 4 & 8 & 2 & 6 & 6 & 14 \\
\hline & 5 & 0 & 0 & 4 & 4 & 4 & 6 & 2 & 12 \\
\hline & 6 & 0 & 0 & 2 & 2 & 0 & 0 & 2 & 2 \\
\hline \multirow[t]{6}{*}{ U12-13 (girls) } & 7 & 0 & 2 & 6 & 8 & 0 & 0 & 0 & 0 \\
\hline & 8 & 6 & 6 & 4 & 16 & 6 & 0 & 2 & 8 \\
\hline & 9 & 2 & 2 & 2 & 6 & 6 & 6 & 0 & 12 \\
\hline & 10 & 0 & 2 & 6 & 8 & 2 & 6 & 6 & 14 \\
\hline & 11 & 2 & 2 & 6 & 10 & 4 & 0 & 6 & 10 \\
\hline & 12 & 0 & 0 & 0 & 0 & 2 & 4 & 2 & 8 \\
\hline Total & & 16 & 22 & 38 & 76 & 32 & 42 & 38 & 112 \\
\hline Total for all players & 35 & 52 & 82 & 90 & $224^{\star}$ & 90 & 110 & 122 & $324^{*}$ \\
\hline
\end{tabular}

${ }^{*} \mathrm{p}<0.05$.

$\mathrm{N}$, number of players.

Table 2 Total number of runs scored before and after the 6-week intervention among coached cricketers $(n=12)$

\begin{tabular}{|c|c|c|c|c|c|c|c|}
\hline \multicolumn{4}{|c|}{ Team A (control group) } & \multicolumn{4}{|c|}{ Team B (experiment group) } \\
\hline Player & Prematch & Postmatch & ES & Player & Prematch & Postmatch & ES \\
\hline $\mathrm{A} 1$ & 10 & 10 & 0 & B1 & 3 & 8 & $1.69^{\star \star}$ \\
\hline A2 & 4 & 5 & 0.33 & B2 & 0 & 4 & $1.35^{\star \star}$ \\
\hline A3 & 1 & 0 & -0.33 & B3 & 4 & 4 & 0 \\
\hline A4 & 0 & 1 & 0.33 & B4 & 4 & 5 & 0.33 \\
\hline A5 & 4 & 4 & 0 & B5 & 0 & 2 & $0.67^{*}$ \\
\hline A6 & 2 & 0 & -0.67 & B6 & 4 & 8 & $1.35^{\star \star}$ \\
\hline Total A & 21 & 20 & -0.33 & Total B & 15 & 31 & $5.41^{\star \star}$ \\
\hline
\end{tabular}

ES>0.5*; ES>0.8**.

$\mathrm{ES}$, effect size. 
Table 3 Classifiers of the backlift before and after the 6-week intervention among coached cricketers $(n=12)$

\begin{tabular}{lllllll}
\hline \multicolumn{2}{l}{ Team A (control group) } & & & \multicolumn{3}{l}{ Team B (experiment group) } \\
\cline { 5 - 6 } Player & Prematch & Postmatch & & Player & Prematch & Postmatch \\
\hline A1 & 1 & 1 & B1 & 1 & 3 \\
A2 & 1 & 1 & B2 & 3 & 3 \\
A3 & 1 & 1 & B3 & 2 & 3 \\
A4 & 3 & 3 & B4 & 2 & 3 \\
A5 & 1 & 1 & B5 & 2 & 3 \\
A6 & 1 & 1 & B6 & 3 & 3 \\
\hline
\end{tabular}

Table 4 Images showcasing the batting backlift techniques of the control group $(n=6)$ over 6 weeks in the frontal plane

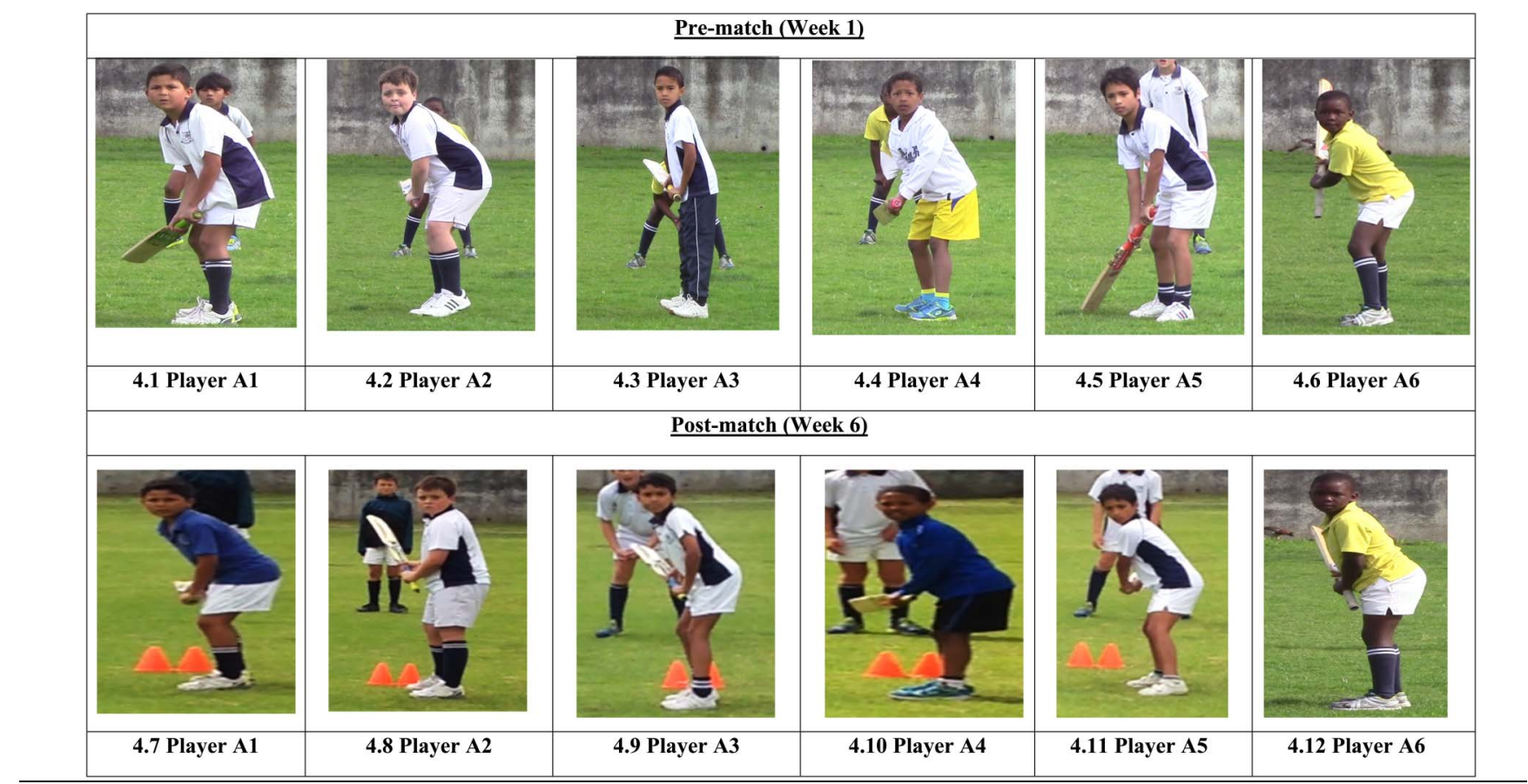

Despite the fact that the coaching cricket bat can assist in performing a more lateral backlift, the hand position in this study was not measured. However, one could argue that in order to open the face of the bat, the bottom hand grip of the player would be more open, which would allow for the player to loop the bat, open the face of the bat and execute a particular batting stroke. Future studies are recommended in this area, specifically on the association of the grip and the batting backlift technique in cricket.

\section{Physical characteristics of the coaching cricket bat and other cricket bats}

Another reason for players hitting the ball more effectively could be due to the weight component and dimensions of the coaching cricket bat, which allows for a superior magnitude of displacement and angular velocity on execution of the shot. ${ }^{25} \mathrm{~A}$ common argument for the model of the coaching cricket bat is that it would be easier for a player to hit the ball due to the wider surface area. Although there is a wider surface area, the weight and angular momentum of the bat on pick up also allows a player to lift the bat in a lateral direction. This may assist a young cricketer to lift their bat wider than second slip with an open face of the bat before making impact with the ball (figure 1).

In conjunction with the weight component, Stretch et $a l,{ }^{25}$ conducted a study to compare the rebound characteristics of wooden and composite cricket bats. The study showed that the rebound characteristics of the composite bats were significantly less than the traditionally designed English willow wooden bats. ${ }^{25}$ In addition, a composite bat does not enhance performance by allowing the batsman to hit the ball harder, assuming all other factors, such as bat speed, mass distribution and the impact point, are equal. Our coaching cricket bat is made from a resin composite material, giving it a lighter weight than the normal bat. Yet junior cricketers were 
Table 5 Images showcasing the batting backlift techniques of the experimental group $(n=6)$ over 6 weeks in the frontal plane

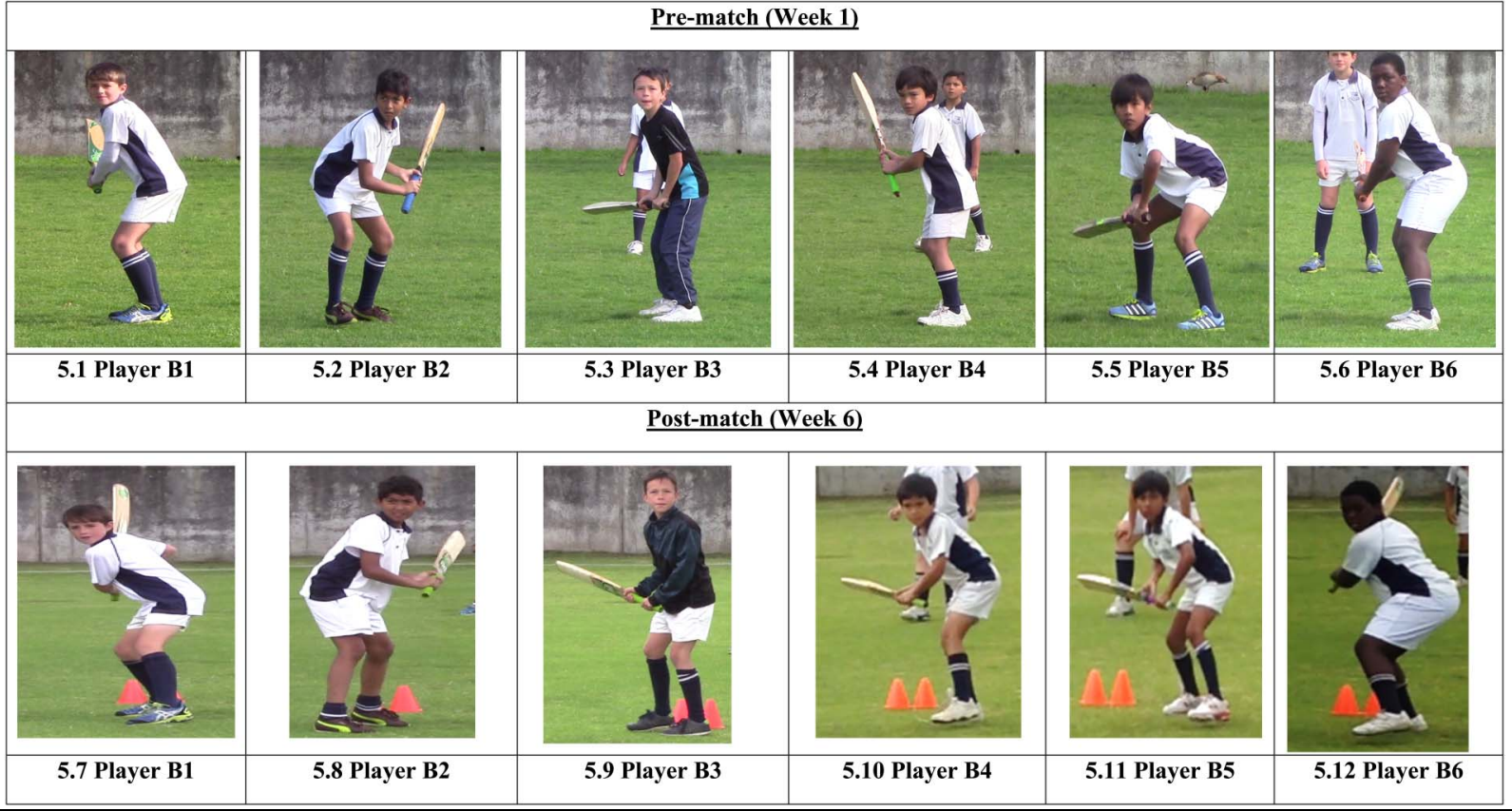

Table 6 Images showcasing the batting backlift techniques of the control group $(n=6)$ over 6 weeks in the transverse plane

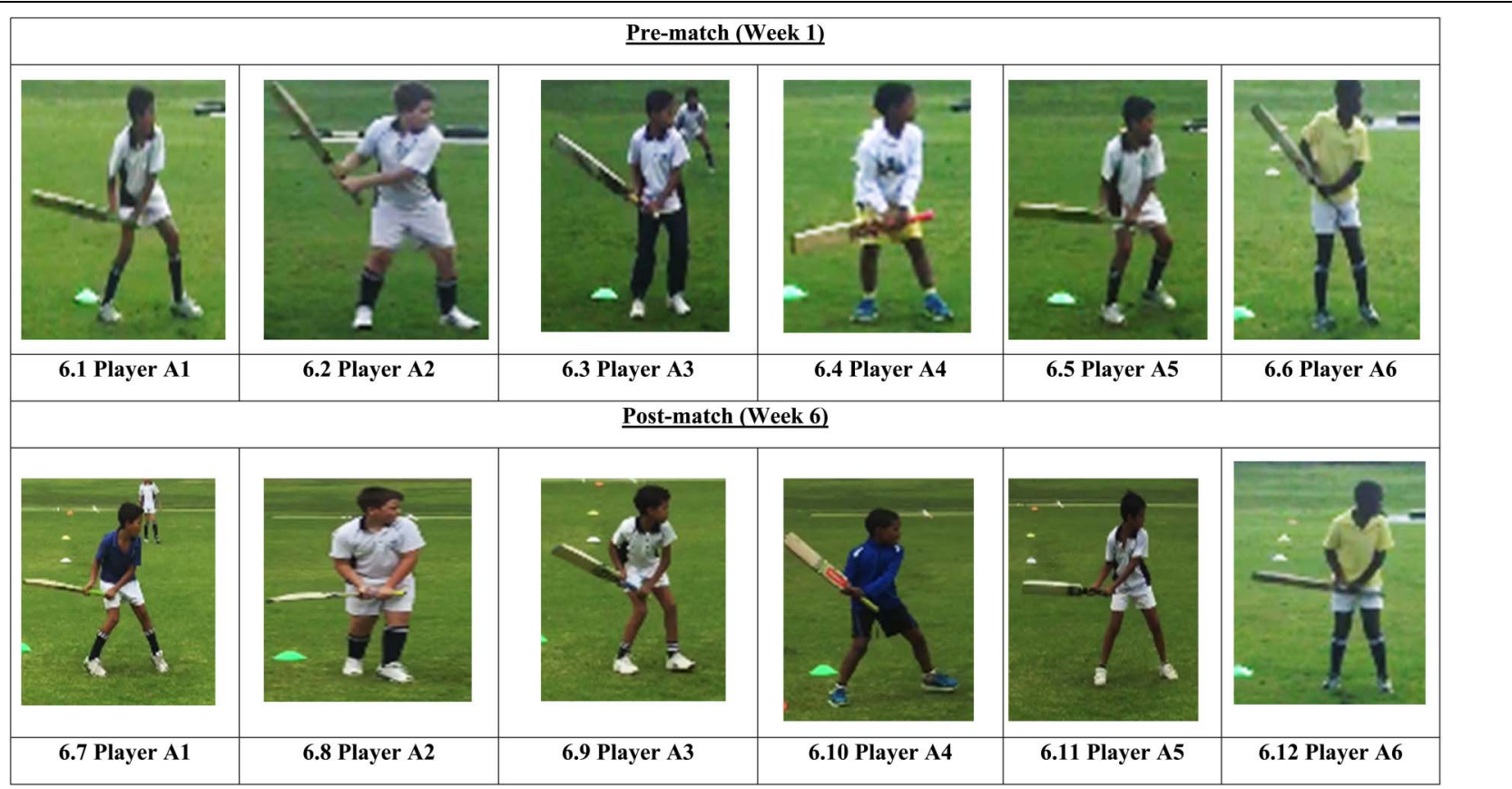

able to score more runs than with the normal bat, and were able to develop a better LBBT after a few weeks. This might suggest that the weight of the coaching cricket bat (and not merely the design) is a key precursor for why young players are able to effectively hit the ball.

With similar dimensions and weight characteristics, aluminium and wooden bats have similar static balance and resistance to rotary motion. ${ }^{27}$ The fundamental question here is: why would one want to resist the rotary motion of a bat when previous studies have shown that a majority of successful batsmen used a lateral backlift or a 'looped/rotary' motion? ${ }^{18}$ Aluminium bats have significantly larger reaction impulses at all impact sites compared with wooden bats. In addition, senior cricketers 
Table 7 Images showcasing the batting backlift techniques of the experimental group $(n=6)$ over 6 weeks in the transverse plane

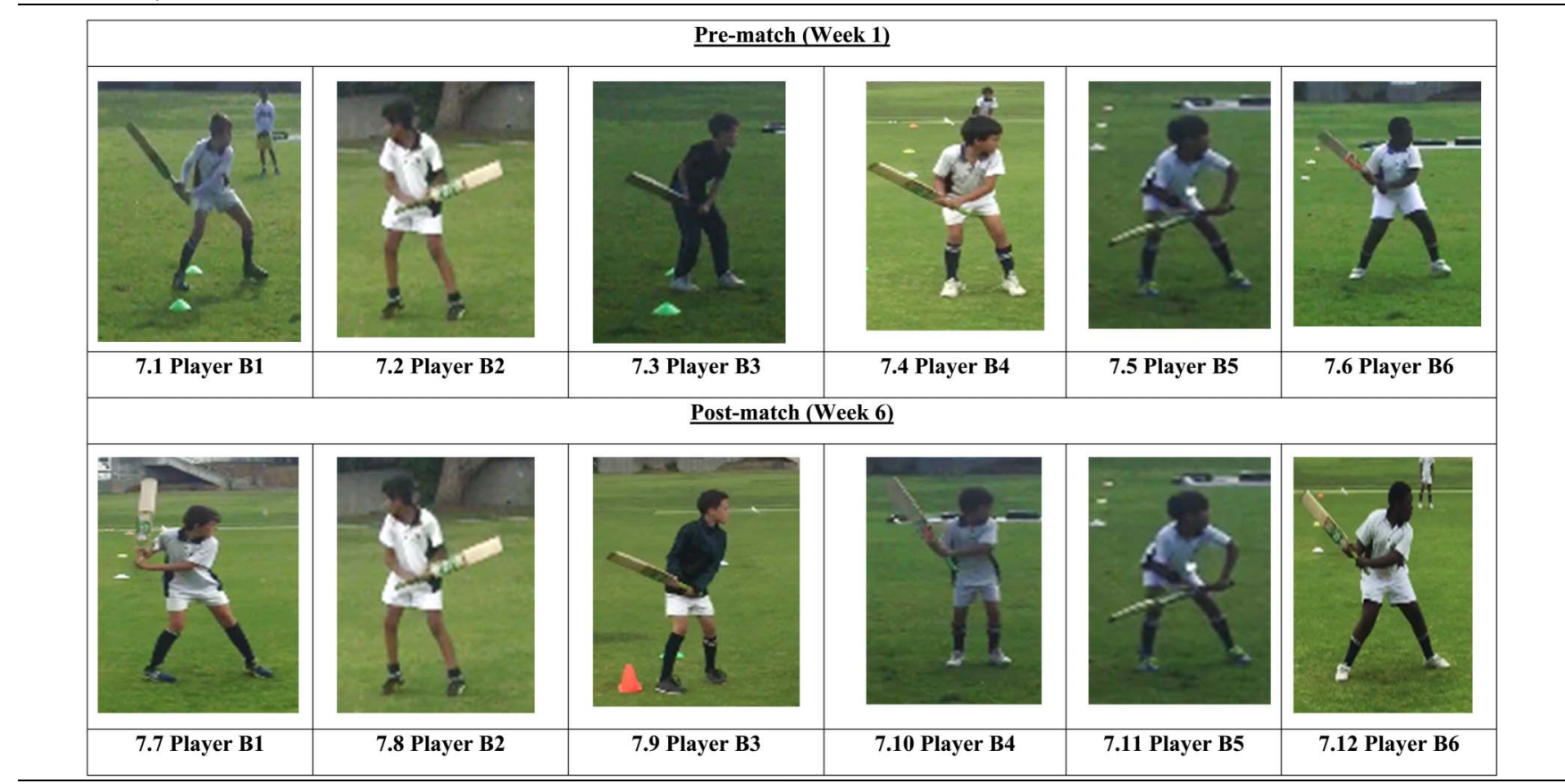

recorded significantly greater rebound values at three of the four impact locations when using an aluminium bat. Junior wooden bats had superior rebound values to the aluminium bats in two of the four impact sites. ${ }^{26}$

Therefore, it is evident that the composition, dimensions and weight of cricket bats may have a significant effect on a batsman. Specifically with young cricket players, the coaching cricket bat may represent an effective tool to specifically assist in the backlift and performance.

\section{Strengths and limitations}

One strength of this study was the ability to capture videos for both groups of participants analysing various ball deliveries for each participant and performing analysis in the frontal and transverse planes. Another strength was that each group of participants played in the same environment and in the same month, which limited the potential effect of season. Biomechanical and video analysis of the players was also obtained objectively (as opposed to being self-reported). The main limitation of our study was the sample number in the intervention study group. Initially, 20 participants had been recruited, but closer to the time, 8 participants dropped out. However, we had accounted for recruiting 20 participants in case of such a dropout where more than 10 participants would still have been available for accurate and reliable analyses. In addition, the pilot group $(n=35)$ supported the sample number of the intervention cohort $(n=12)$. In order to support correct classifications of the backlift, validity and reliability were established by using an inter-rater (another person). Furthermore, we accounted for perspective error by limiting the type of videos observed and including horizontal lines in the background.

\section{CONCLUSION}

The coaching cricket bat may be a promising training aid to train young cricket batsmen (ages 5-11) in order to develop the potential for striking the ball with power and timing. The coaching cricket bat, together with the training drill of hitting the ball against the wall, may have a positive effect on the backlift used by young cricketers, particularly if used for a minimum of 4 weeks. However, our findings are not conclusive and further research needs to be conducted with the coaching cricket bat over a season among young cricket players.

Acknowledgements The authors would like to extend their gratitude to the participants and their parents/guardians as well as the cricket coaches for their participation and assistance in the study.

Contributors HN designed the study, performed the data collection and analysis of the participants and wrote the manuscript. RCW designed the coaching cricket bat, assisted with data collection and supplied the graphics of most of the figures. TDN conceptualised the coaching cricket bat, assisted in the design of the study, and assisted in the write-up of the manuscript.

Funding This research study was partially funded by a University Research Fund from the Cape Peninsula University of Technology as well as the Bob Woolmer 149 Trust Fund.

Competing interests None declared.

Patient consent Obtained.

Ethics approval Human Research Ethics Committee, Faculty of Health Sciences, University of Cape Town.

Provenance and peer review Not commissioned; externally peer reviewed.

Data sharing statement No additional data are available. 
Open Access This is an Open Access article distributed in accordance with the Creative Commons Attribution Non Commercial (CC BY-NC 4.0) license, which permits others to distribute, remix, adapt, build upon this work noncommercially, and license their derivative works on different terms, provided the original work is properly cited and the use is non-commercial. See: http:// creativecommons.org/licenses/by-nc/4.0/

\section{REFERENCES}

1. Stretch RA, Bartlett RM, Davids K. A review of batting in men's cricket. J Sports Sci 2000;18:931-49.

2. Noorbhai $\mathrm{MH}$, Noakes TD. Advancements in cricket in the $21 \mathrm{st}$ century: science, performance and technology. Afr J Phys Health Educ Recreation Dance 2015;21:1321-31.

3. McLean SP, Reeder MS. Upper extremity kinematics of dominant and non-dominant side batting. J Hum Mov Stud 2000;38:201-12.

4. Davis K. Discovering biomechanical principles of batting in cricket In: Matsui $\mathrm{H}$, Kobayashi K, eds, Biomechanics VIII-B: Proceedings of the Eighth International Congress of Biomechanics. Champaign: Human Kinetics, 1983:915-22.

5. Gibson AP, Adams RD. Batting stroke timing with a bowler and a bowling machine: a case study. Aust J Sci Med Sport 1983;21:3-6.

6. Kreighbaum E, Barthels KM. Biomechanics: a qualitative approach for studying human movement. 4th edn. Boston: Allyn \& Bacon, 1996.

7. Gelinas M, Hoshizaki TB. Kinematic characteristics of opposite field hitting. In: Kreighbaum E, McNeil A, eds. Biomechanics in Sports VI: Proceedings of the 6th International Symposium on Biomechanics in Sports. Bozeman: Montana State University, 1988:519-30.

8. Handford C, Davids K, Bennett S, et al. Skill acquisition in sport: some applications of an evolving practice ecology. J Sports Sci 1997:15:621-40.

9. Mullineaux DR, Bartlett RM, Bennett S. Research design and statistics in biomechanics and motor control. J Sports Sci 2001;19:739-60.
10. Fry CB. Cricket: batsmanship. London: Eveleigh Nash, 1912.

11. The MCC. The M.C.C. Cricket Coaching Book. William Heinemann Ltd, 1954.

12. Boycott G, Gower D. Batting Vivian Richards. Chapter (MCC), 1994

13. Chappell G. Cricket: the making of champions. Brewster Publisher, 2004.

14. Woolmer B. Skilful cricket. London: A \& C Black, 1993.

15. Woolmer B, Noakes TD, Moffett H. Bob Woolmer's Art and Science of cricket. Cape Town: Struik Publishers, 2009.

16. Palmer G. Cricket coachmaster batting mechanics. The Baulch Grou, 1999

17. Tyson F. Complete cricket coaching. Pelham Books Ltd, 1976

18. Noorbhai MH, Noakes TD. A descriptive analysis of batting backlift techniques in cricket: does the practice of elite cricketers follow the theory? J Sports Sci 2016;34:1930-40.

19. Stuelcken MC, Portus MR, Mason BR. Off-side front foot drives in men's high performance cricket. Sports Biomech 2005;4 17-35.

20. Noorbhai MH, Noakes TD. An analysis of batting backlift techniques among coached and uncoached cricket batsmen. S Afr J Res Sport Phys Educ Recreation 2016.

21. Portus MR, Farrow D. Enhancing cricket batting skill: implications for biomechanics and skill acquisition research and practice. Sports Biomech 2011;10:294-305.

22. Glazier PS, Davids K, Bartlett RM. Dynamical systems theory: a relevant framework for performance-orientated sports biomechanics research. 2003. http://Sportsci.org/index.html?jour/o3/03.htm\& 1 (accessed 31 Oct 2015).

23. Hopkins WG. Measures of reliability in sports medicine and science. Sports Med 2000;30:1-15.

24. Sullivan GM, Feinn R. Using effect size-or why the $p$ value is not enough. J Grad Med Educ 2012;4:279-82.

25. Stretch RA, Brink A, Hugo J. A comparison of the ball rebound characteristics of wooden and composite cricket bats at three approach speeds. Sports Biomech 2005;4:37-45.

26. Elliott BC, Ackland TA. Physical and impact characteristics of aluminium and wood cricket bats. J Hum Mov Stud 1982;8:149-57. 